\title{
ANÁLISE DA PRODUÇÃO TÉCNICO-CIENTÍFICA DOS BOLSISTAS DE PRODUTIVIDADE DO CNPQ DA ÁREA DE EDUCAÇÃO FÍSICA NO TRIÊNIO 2010-2012
}

\author{
Bruno Pedroso \\ Universidade Estadual de Ponta Grossa, Ponta Grossa, Paraná, Brasil \\ Guilherme Moreira Caetano Pinto \\ Universidade Estadual de Ponta Grossa, Ponta Grossa, Paraná, Brasil \\ Claudia Tania Picinin \\ Universidade Tecnológica Federal do Paraná, Ponta Grossa, Paraná, Brasil \\ Gustavo Luis Gutierrez \\ Universidade Estadual de Campinas, Campinas, São Paulo, Brasil
}

\begin{abstract}
Resumo
O presente estudo objetivou analisar a produção técnico-científica dos bolsistas de produtividade da área da Educação Física no triênio 2010-2012. A relação de bolsistas de produtividade foi obtida por meio da página eletrônica do CNPq, tendo sido posteriormente buscados seus currículos na Plataforma Lattes e contabilizadas, por meio do software scriptLattes v8.07, sua produção bibliográfica, técnica e artística e as orientações concluídas. Constatou-se que estes visam prioritariamente publicações em periódicos de Qualis A1, A2 e B1, bem como orientações de mestrado e doutorado. Conclui-se que os bolsistas de produtividade da área da Educação Física tendem a direcionar suas produções para atender aos requisitos estipulados pelo CNPq para manutenção/ascensão da bolsa de produtividade.
\end{abstract}

Palavras-chave: Apoio à pesquisa. Indicadores de produção científica. Educação Física e treinamento.

\section{Introdução}

Os pesquisadores bolsistas de produtividade do Conselho Nacional de Desenvolvimento Científico e Tecnológico $(\mathrm{CNPq})$ compõem um grupo de referência no meio acadêmico brasileiro. À bolsa de produtividade tem sido atribuído o status de prêmio, de reconhecimento por uma atuação de destaque na construção do conhecimento na área de atuação dos pesquisadores bolsistas.

Estas se classificam em bolsa de produtividade em pesquisa (PQ) e bolsa de produtividade em desenvolvimento tecnológico e extensão inovadora (DT). Nestas modalidades, há as categorias sênior, 1 e 2 . Em linhas gerais, a categoria 2 é considerada inicial e seu processo de seleção considera as produções do pesquisador com ênfase em trabalhos publicados e orienta-

\footnotetext{
${ }^{1} \mathrm{O}$ presente trabalho não contou com apoio financeiro de nenhuma natureza para sua realização.
} 
ções no período dos cinco últimos anos. Já nas bolsas da categoria 1 , o processo para a sua concessão considera a produtividade do pesquisador nos dez últimos anos, havendo uma subdivisão entre os níveis $\mathrm{A}, \mathrm{B}, \mathrm{C}$, e $\mathrm{D}$, de forma que o nível A é o mais elevado. A categoria sênior destina-se aos pesquisadores que se destacam como líderes em sua área de atuação, sendo exigido que o profissional tenha se mantido por no mínimo 15 anos na categoria 1 , em nível A ou B.

O CNPq apresenta diversos critérios, gerais e específicos, para a aquisição da bolsa. Quanto às exigências gerais, há a necessidade de que o pesquisador tenha uma linha definida, apresente projeto de pesquisa de mérito científico e atinja a classificação compatível com a cota de bolsas disponíveis na categoria.

No que concerne aos critérios específicos para a área da Educação Física, o CNPq apresenta distinções nas exigências para a concessão das bolsas de categoria 1 e 2 . Para a concessão de bolsas categoria 2, os critérios são: ter concluído o doutorado há no mínimo três anos; ter publicado ao menos cinco trabalhos científicos em periódicos científicos indexados minimamente nas bases LILACS, EMBASE ou ERIC, sendo que em três destes trabalhos o pesquisador deve ser autor principal ou o orientador (segunda ou última posição); ter concluído a orientação de pelo menos um mestre e estar em atividade de pesquisa e de orientação de mestrandos ou doutorandos (CNPq, 2010).

Já para a concessão de bolsas de categoria 1, no nível 1D, o CNPq apresenta os seguintes critérios: ter concluído o doutorado há no mínimo oito anos; ter publicado pelo menos 20 trabalhos científicos em periódicos indexados minimamente nas bases LILACS, EMBASE ou ERIC, sendo que cinco desses trabalhos devem ter indexação mínima na base SciELO e, em pelo menos dez desses trabalhos, o pesquisador deve ser o autor principal ou o orientador (segunda ou última posição); ter concluído a orientação de pelo menos três mestres ou doutores; estar em atividade de pesquisa e de orientação de pelo menos três mestrandos ou doutorandos (CNPq, 2010).

Para a concessão de bolsa nível 1C, 1B e 1A, os critérios são: ter concluído o doutorado há no mínimo oito anos; ter publicado pelo menos 20 trabalhos científicos com indexação mínima nas bases SciELO, LILACS, EMBASE ou ERIC, sendo que pelo menos cinco destes devem ter indexação nas bases MEDLINE ou ISI e em pelo menos dez desses trabalhos o pesquisador deve ser o autor principal ou o orientador (segunda ou última posição); ter concluído a orientação de no mínimo cinco mestres ou doutores, sendo no mínimo dois doutores; estar em orientação de pelo menos três mestrandos ou doutorandos (CNPq, 2010).

$\mathrm{O} \mathrm{CNPq}$, por meio das métricas descritas, visa avaliar e premiar os pesquisadores por meio das bolsas de produtividade. Neste contexto, torna-se necessária uma reflexão da comunidade acadêmica sobre esses indicadores de desempenho, bem como sobre as formas de atingi-los. A partir desta premissa, as seguintes áreas apresentam pesquisas de mapeamento dos bolsistas de produtividade: Administração e Contabilidade (OLIVEIRA et al., 2007), Odontologia (SCARPELLI et al., 2008), Saúde Coletiva (SANTOS et al., 2009), Medicina (MARTELLI-JUNIOR et al., 2010; MENDES et al., 2010), Nefrologia e Urologia (OLIVEIRA et al., 2011a), Cardiologia (OLIVEIRA et al., 2011b) e Medicina Veterinária (SPILKI, 2013). Na área da Educação Física, Leite et al. (2012) buscaram traçar o perfil de bolsistas de produtividade entre os anos de 2007 e 2009.

A área da Educação Física, no que tange às competências voltadas a seu campo de intervenção, caracteriza-se por ser uma área extensa, complexa e heterogênea, com objeto de estudo de natureza multi/interdisciplinar (FURTADO; NAMAN, 2014; PAIXÃO, CUSTÓDIO; BARROSO, 2014). Um ponto central nesse contexto é o fato de a área abarcar distintas ramificações, em especial, entre as formações nos cursos de licenciatura e bacharelado. Sendo assim, compreender as produções acadêmicas dos professores bolsistas de produtividade da 
área da Educação Física enriquece a discussão sobre as métricas existentes para a concessão da bolsa, tendo em vista que esta é uma área com características peculiares.

Diante do contexto apresentado, o objetivo do presente estudo é, em subsequência ao estudo realizado por Leite et al. (2012), analisar a produção técnico-científica de bolsistas de produtividade da área da Educação Física no triênio de 2010 a 2012 de avaliação da pósgraduação stricto sensu no Brasil, realizada pela Coordenação de Aperfeiçoamento de Pessoal de Ensino Superior (CAPES).

Convém destacar que os números, assim como as análises apresentadas no texto, refletem uma realidade em constante transformação, em que sujeitos sociais desenvolvem uma dinâmica de adaptação e de busca no sentido de otimizar resultados, ilustrando a competição que caracteriza o campo da pesquisa científica (GUTIERREZ, 2005).

\section{Metodologia}

Para a obtenção da lista de pesquisadores com bolsa de produtividade na área de Educação Física, realizou-se uma consulta na página eletrônica do CNPq. Em seguida, após a obtenção dos nomes da referida lista e de suas respectivas modalidades, categorias e nível de bolsa, buscou-se na Plataforma Lattes os currículos dos pesquisadores em questão. Tal listagem foi obtida no mês de agosto do ano de 2013.

Findada essa etapa, contabilizaram-se no currículo Lattes de todos os bolsistas de produtividade da Educação Física na ocasião, por meio do software scriptLattes v8.07 (MENACHALCO, 2009), as seguintes publicações acadêmicas: artigos completos em congressos; livros; coletâneas; capítulos de livro; produções técnicas; produções artísticas; orientações de mestrado; orientações de doutorado; orientações de trabalhos de conclusão de curso de graduação (TCC); orientações de iniciação científica; supervisões de pós-doutorado; artigos completos publicados em periódicos.

Em se tratando dos artigos completos publicados em periódicos, estes foram classificados de acordo com o Qualis 2012 da área da Educação Física, vigente na ocasião, obtido por meio da página eletrônica do Qualis CAPES (CAPES, 2013).

\section{Resultados e discussão}

Após a referida busca, constatou-se que a área da Educação Física contava com 88 bolsistas de produtividade em pesquisa na ocasião. Destes, 28 pertenciam à categoria 1 , sendo 5 no nível 1A, 3 no nível 1B, 7 no nível $1 \mathrm{C}$ e 13 no nível 1D, enquanto outros 60 pesquisadores pertenciam à categoria 2. Não havia nenhum bolsista na categoria sênior bem como na modalidade de bolsista de produtividade em desenvolvimento tecnológico e extensão inovadora.

A análise dos dados retornados irá discorrer separadamente sobre as distintas formas de publicações acadêmicas efetuadas pelos bolsistas de produtividade em suas diferentes categorias, buscando facilitar a compreensão das futuras conclusões.

No intento de padronizar a denominação e evitar distorções de análise, utilizar-se-á o termo "categoria" quando houver referência às categorias de bolsa 1, 2 e o termo "nível" quando houver referência à classificação da bolsa na categoria $1(1 \mathrm{~A}, 1 \mathrm{~B}, 1 \mathrm{C}, 1 \mathrm{D})$.

A discussão será apresentada, em um primeiro momento, quanto ao número absoluto de ocorrências de publicações ou orientações em relação à categoria dos bolsistas, e, posteriormente, pela média de itens por bolsista em cada categoria, pois, desta forma, julga-se obter maior possibilidade de inferência de considerações. 
A Tabela 1 apresenta as ocorrências de publicações de artigos completos publicados em congressos em âmbito nacional e internacional em relação ao nível dos bolsistas de produtividade:

Tabela 1 - Número de ocorrência de artigos completos publicados em congressos nacionais e internacionais em relação ao nível dos bolsistas de produtividade.

\begin{tabular}{lcc}
\hline & INTERNACIONAL & NACIONAL \\
\hline 1A & 0 & 0 \\
1B & 1 & 1 \\
1C & 12 & 5 \\
1D & 0 & 9 \\
2 & 35 & 69 \\
\hline
\end{tabular}

Fonte: Autoria própria, 2015

Observa-se que, em geral, o número de ocorrência nas publicações em congressos é relativamente pequeno. Bolsistas de nível 1A não publicaram artigos em congressos no período investigado e, de forma similar, bolsistas de nível 1B não apresentaram uma tendência em publicar em congressos nacionais (1) ou internacionais (1), sugerindo que estas ocorrências se tratam de uma provável eventualidade. Bolsistas de nível 1C apresentaram maior quantidade de publicação em congressos internacionais (12) em relação a congressos nacionais (5). Em contrapartida, bolsistas de nível 1D priorizaram publicações em congressos nacionais (9) em relação a congressos internacionais (0). Em medida semelhante, bolsistas da categoria 2 apresentaram uma maior quantidade de publicações em congressos nacionais (69).

Publicações em congressos não contabilizam para a concessão da bolsa de produtividade ou ascensão de categoria/nível desta. Parece estar evidenciado que os pesquisadores bolsistas de produtividade não priorizam publicações neste meio, fato que justifica o presente cenário.

A Tabela 2 apresenta as médias de publicações de artigos completos publicados em congressos em âmbito nacional e internacional em relação ao nível dos bolsistas de produtividade:

Tabela 2 - Média de artigos completos publicados em congressos nacionais e internacionais em relação ao nível dos bolsistas de produtividade.

\section{INTERNACIONAL NACIONAL}

\begin{tabular}{lcc}
\hline $\mathbf{1 A}$ & 0 & 0 \\
$\mathbf{1 B}$ & 0,33 & 0,33 \\
$\mathbf{1 C}$ & 1,71 & 0,71 \\
$\mathbf{1 D}$ & 0 & 0,69 \\
$\mathbf{2}$ & 0,58 & 1,15 \\
\hline
\end{tabular}

Fonte: Autoria própria, 2015

Tal qual observado na Tabela 1, não é possível identificar uma tendência nas médias de publicação em congressos no âmbito nacional e internacional por parte dos diferentes níveis de bolsistas de produtividade. Não obstante, os valores encontram-se próximos, algo que sugere um interesse similar nesta modalidade de publicações, por conseguinte baixo em todos os níveis.

O estudo de Picinin (2014), ao analisar a produção de artigos completos publicados em congressos dos bolsistas de produtividade da área da Administração, constatou que os pesquisadores bolsistas de produtividade vigentes direcionam suas produções de acordo com os cri- 
térios necessários para manutenção e/ou para obter ascensão no nível/categoria da bolsa de produtividade.

Tal perspectiva coaduna com o cenário encontrado na área da Educação Física, sugerindo que esta é uma tendência que pode se replicar em demais áreas do conhecimento. Em outras palavras, os pesquisadores bolsistas de produtividade realizam suas produções de forma estratégica, de acordo com as regras estabelecidas pelo CNPq para atingir seus objetivos pessoais de manutenção e progressão da bolsa.

A Tabela 3 apresenta o número de ocorrência nas publicações de livros, coletâneas e capítulos de livros em relação ao nível dos bolsistas de produtividade:

Tabela 3 - Número de ocorrência de publicações de livros, coletâneas e capítulos de livros em relação ao nível dos bolsistas de produtividade.

\section{LIVROS COLETÂNEAS CAPÍTULOS}

\begin{tabular}{lclc}
\hline $\mathbf{1 A}$ & 1 & 0 & 2 \\
$\mathbf{1 B}$ & 1 & 0 & 3 \\
$\mathbf{1 C}$ & 3 & 1 & 11 \\
$\mathbf{1 D}$ & 8 & 2 & 25 \\
$\mathbf{2}$ & 10 & 8 & 73 \\
\hline
\end{tabular}

Fonte: Autoria própria, 2015

Em geral, tal qual nas publicações de congresso, o número de ocorrências nesta categoria de publicações não foi expressivo. Isto é um indicativo de que pesquisadores de todos os níveis de bolsa publicaram em maior quantidade capítulos de livros, seguidos por livros, e, por fim, coletâneas. Tal panorama pode ter relação direta com o tempo demandado para a consecução da publicação, haja vista que os capítulos de livro tendem a requerem menor tempo para a sua elaboração.

A Tabela 4 apresenta as médias nas publicações de livros, coletâneas e capítulos de livros em relação à categoria do bolsista de produtividade:

Tabela 4 - Médias de ocorrência nas publicações de livros, coletâneas e capítulos de livros em relação ao nível dos bolsistas de produtividade.

\section{LIVROS COLETÂNEAS CAPÍTULOS}

\begin{tabular}{lccc}
\hline $\mathbf{1 A}$ & 0,2 & 0 & 0,4 \\
$\mathbf{1 B}$ & 0,33 & 0 & 1 \\
$\mathbf{1 C}$ & 0,43 & 0,14 & 1,57 \\
$\mathbf{1 D}$ & 0,62 & 0,15 & 1,92 \\
$\mathbf{2}$ & 0,17 & 0,13 & 1,22 \\
\hline
\end{tabular}

Fonte: Autoria própria, 2015.

As publicações de livros e capítulos de livro apresentam uma tendência linear de aumento inversamente proporcional aos níveis da categoria 1. Entretanto, a categoria 2 não segue a continuidade desta linearidade. Tal qual ocorre nas publicações de coletâneas, em que não se pode observar linearidade, seja esta direta, seja esta inversa.

No triênio de 2007 a 2009, Leite et al. (2012) constataram que os 74 bolsistas de produtividade publicaram 100 livros (média de 1,4 por pesquisador) e 342 capítulos de livro (média de 4,6 por pesquisador). No presente estudo, verificou-se que, no período de 2010 a 2012, os 88 bolsistas de produtividade publicaram 23 livros (média de 0,31 por pesquisador) e 114 capítulos de livro (média de 1,29 por pesquisador). 
Logo, verifica-se que houve uma queda acentuada no número de publicações de livros e capítulos de livro no período de 2010 a 2012 em relação ao período de 2007 a 2009. Destaca-se ainda que, mesmo que o número de pesquisadores com bolsa de produtividade no período de 2007 a 2009 (74) tenha sido inferior ao período de 2010 a 2012 (88), o número de livros e capítulos de livros publicados foi consideravelmente superior.

Tal cenário coaduna com o fenômeno de adaptação dos pesquisadores a fim de otimizar seus resultados, previsto por Gutierrez (2005). A publicação de livros e capítulos de livros não é um critério para a concessão de bolsas de produtividade (CNPq, 2010). Desta forma, ao que parece, os pesquisadores adaptaram-se às métricas e passaram a destinar menos tempo para a confecção de livros e capítulos.

Considerando individualmente as categorias e níveis de bolsa, uma investigação na área da Administração reportou que os bolsistas de produtividade também publicaram em maior quantidade capítulos de livros (PICININ, 2014). Na área de Saúde Coletiva, foi constatado que bolsistas de nível 1A publicaram livros em maior quantidade, enquanto bolsistas de nível 1D publicaram em maior quantidade capítulos de livros (SANTOS et al., 2009). Antagonicamente, na área da Medicina, enquanto os pesquisadores de nível 1A publicaram em maior quantidade capítulos de livros, os bolsistas de nível 1B publicaram em maior quantidade livros (MENDES et al., 2010).

No caso da Educação Física, no período de 2007 a 2009, verificou-se que os bolsistas de nível 1C (média de 2,3 livros e 7,6 capítulos de livro por pesquisador) e 1D (média de 1,7 livro e 7,1 capítulos de livros por pesquisador) destacaram-se na publicação de livro e capítulo de livro (LEITE et al., 2012).

Já no período de 2010 a 2012, verificou-se que os pesquisadores de nível 1C e 1D também se destacaram na publicação de livros e capítulos de livro. Desta forma, este cenário não parece ter se alterado no triênio subsequente. Além disso, em todas as categorias de bolsa de produtividade, houve publicações em maior quantidade de capítulos de livro em comparação aos livros e coletâneas. Neste sentido, o cenário aproxima-se de pesquisadores da área da Administração (PICININ, 2014) e da Educação Física no triênio de 2007 a 2009 (LEITE et al., 2012).

Assim como ocorre com as publicações em congressos, publicações de livros, coletâneas e capítulos de livro não fazem parte das exigências para a concessão de bolsa de produtividade. Este fator, acrescido da demanda de tempo geralmente maior na confecção destas publicações, pode explicar de forma plausível o número reduzido de publicação nestes itens.

A Tabela 5 apresenta o número de ocorrência das produções técnicas e artísticas em relação ao nível dos bolsistas de produtividade:

Tabela 5 - Número de ocorrência de produções técnicas e artísticas em relação ao nível dos bolsistas de produtividade.

\begin{tabular}{lccc}
\hline & TÉCNICA & ARTÍSTICA \\
\hline 1A & 71 & 0 \\
1B & 2 & 0 \\
1C & 59 & 0 \\
1D & 141 & 2 \\
$\mathbf{2}$ & 461 & 1 \\
\hline
\end{tabular}

Fonte: Autoria própria, 2015

Nas produções técnicas, verifica-se a incidência de números relativamente elevados considerando que na ocasião havia no Brasil apenas um mestrado profissional na área da Educação Física e que não há bolsistas de produtividade em desenvolvimento tecnológico e extensão inovadora na referida área - em todos os níveis de bolsistas de produtividade, excetu- 
ando-se o nível 1B. A produção artística, por sua vez, é nula ou muito pequena em todos os níveis de bolsistas de produtividade, o que não representa uma anormalidade, na medida em que estas comumente não são desenvolvidas no âmbito da Educação Física.

A Tabela 6 apresenta as médias de ocorrência das produções técnicas e artísticas em relação ao nível dos bolsistas de produtividade:

Tabela 6 - Número de ocorrência de produções técnicas e artísticas em relação ao nível dos bolsistas de produtividade.

\begin{tabular}{lcc}
\hline & TÉCNICA & ARTÍSTICA \\
\hline $\mathbf{1 A}$ & 14,2 & 0 \\
$\mathbf{1 B}$ & 0,67 & 0 \\
$\mathbf{1 C}$ & 8,43 & 0 \\
$\mathbf{1 D}$ & 10,85 & 0,15 \\
$\mathbf{2}$ & 7,68 & 0,017 \\
\hline
\end{tabular}

Fonte: Autoria própria, 2015

A limitada ocorrência de produções artísticas oriundas dos bolsistas de produtividade em todos os níveis impossibilita uma análise que não seja superficial deste tipo de produção. Com relação às produções técnicas, observa-se a existência de uma oscilação não linear entre os valores retornados nos diferentes níveis de bolsistas de produtividade.

As médias obtidas por bolsistas de nível 1A $(14,2)$ foram superiores em relação a todos os demais níveis de bolsistas investigados, indicando que, mesmo não estando dentro dos requisitos para a concessão da bolsa de produtividade, pesquisadores do nível mais elevado não desconsideram tal tipo de produção. Não obstante, os bolsistas de nível 1C $(8,43)$, $1 \mathrm{D}$ $(10,85)$ e $2(7,68)$ também apresentaram publicações nesta categoria, o que reforça a hipótese de que os pesquisadores bolsistas de produtividade não tendem a cessar sua produção técnica. No entanto, os bolsistas do nível 1B $(0,67)$ não apresentaram valores próximos aos demais níveis de bolsa. Não foi possível identificar uma justificativa plausível para tal exceção.

No mapeamento de mesma natureza realizado na área da Administração (PICININ, 2014), os bolsistas de produtividade obtiveram média de 19,19 no item produção técnica, o qual representa um valor bastante superior ao encontrado na área da Educação Física. Entretanto, cabe-se ressaltar que, na área da Administração, há um número considerável de programas de mestrados profissionais, o qual representa cerca de $70 \%$ do número de programas de mestrados acadêmicos.

A Tabela 7 apresenta os resultados referentes às orientações em relação ao nível dos bolsistas de produtividade:

Tabela 7: Número de ocorrências por categoria de orientação em relação ao nível dos bolsistas de produtividade.

\begin{tabular}{lccccc}
\hline & $\begin{array}{c}\text { PÓS- } \\
\text { DOUTORADO }\end{array}$ & DOUTORADO & MESTRADO & TCC & $\begin{array}{c}\text { INICIAÇÃO } \\
\text { CIENTÍFICA }\end{array}$ \\
\hline $\mathbf{1}^{\mathbf{a}}$ & 5 & 10 & 15 & 5 & 14 \\
$\mathbf{1 B}$ & 1 & 11 & 8 & 2 & 3 \\
$\mathbf{1 C}$ & 6 & 18 & 26 & 8 & 9 \\
$\mathbf{1 D}$ & 6 & 23 & 49 & 23 & 26 \\
$\mathbf{2}$ & 8 & 65 & 265 & 340 & 288 \\
\hline
\end{tabular}

Fonte: Autoria própria, 2015 
De maneira geral, verifica-se que as orientações estão presentes em todos os níveis dos bolsistas de produtividade. Com exceção dos bolsistas nível 1B, nos demais grupos as orientações de mestrado foram mais numerosas do que as orientações de doutorado, que, por sua vez, foram mais numerosas do que as supervisões de pós-doutorado. Já as orientações de TCC e iniciação científica são mais frequentes no nível 1D e categoria 2 de bolsa de produtividade. As supervisões de pós-doutorado, por sua vez, são proporcionalmente menores do que as demais orientações nos níveis $1 \mathrm{~B}, 1 \mathrm{D}$ e categoria 2.

A Tabela 8 apresenta as médias em relação às orientações em relação ao nível dos bolsistas de produtividade:

Tabela 8: Número de ocorrências por categoria de orientação em relação ao nível dos bolsistas de produtividade.

\begin{tabular}{cccccc}
\hline & $\begin{array}{c}\text { PÓS- } \\
\text { DOUTORADO }\end{array}$ & DOUTORADO & MESTRADO & TCC & $\begin{array}{c}\text { INICIAÇÃO } \\
\text { CIENTÍFICA }\end{array}$ \\
\hline $\mathbf{1 A}$ & 1 & 2 & 3 & 1 & 2,8 \\
$\mathbf{1 B}$ & 0,33 & 3,67 & 2,67 & 0,67 & 1 \\
$\mathbf{1 C}$ & 0,86 & 2,57 & 3,71 & 1,14 & 1,29 \\
$\mathbf{1 D}$ & 0,46 & 1,77 & 3,77 & 1,77 & 2 \\
$\mathbf{2}$ & 0,13 & 1,08 & 4,42 & 5,67 & 4,8 \\
\hline
\end{tabular}

Fonte: Autoria própria, 2015

Verifica-se que há uma certa uniformidade na distribuição dos distintos tipos de orientações nos bolsistas nível 1A. Já nos bolsistas de nível 1B e 1C, verifica-se que a média de orientações de mestrado e doutorado é consideravelmente superior às demais, sendo o grupo dos bolsistas 1B o único em que a média de orientações de doutorado foi superior à média de orientações de mestrado. A partir do nível 1D, verifica-se maior disparidade entre a média de orientações de mestrado e doutorado. Os bolsistas da categoria 2 apresentam concentração das orientações em mestrado, iniciação científica e TCC, sendo este o único grupo em que as orientações de TCC e iniciação científica são mais numerosas do que as orientações de mestrado e doutorado.

As supervisões de pós-doutorado não apresentaram uma tendência, tendo em vista que a maior média encontrada foi em bolsistas nível 1A (1) e a menor média encontrada em bolsistas da categoria $2(0,13)$. Os valores foram inconstantes para bolsistas nível 1B $(0,33), 1 \mathrm{C}$ $(0,86)$ e $1 \mathrm{D}(0,46)$. Pondera-se que, de maneira geral, as supervisões de pós-doutorado são escassas, o que justifica a ausência de uma tendência.

Verifica-se nas orientações de doutorado que, excetuando-se o grupo de bolsistas nível 1A, houve uma tendência de que, na medida em que o nível dos bolsistas 1B diminui, a média de orientação em nível de doutorado também é diminuída, indicando um cenário de variação diretamente proporcional.

Desta forma, pode-se aventar a hipótese de que as orientações em nível de doutorado tendem a ocorrer mais frequentemente em bolsistas de nível 1A, 1B e 1C. Tal fenômeno pode ser justificado pela exigência imposta para estes pesquisadores de que, para a concessão de bolsas nestes níveis, é requisito a orientação de cinco mestres ou doutores, sendo minimamente de dois doutores. Isto naturalmente maximiza as orientações de doutorado entre tais pesquisadores.

Ainda que com valores próximos, as médias de orientações de mestrado, com exceção dos bolsistas nível 1A, tendem a se elevar na medida em que o nível da bolsa diminui, sendo, portanto, inversamente proporcional ao nível da bolsa. 
As orientações de TCC apresentaram valores muito próximos em bolsistas de nível $1 \mathrm{~A}$ $(1), 1 \mathrm{~B}(0,67), 1 \mathrm{C}(1,14)$ e 1D $(1,77)$. Os bolsistas categoria $2(5,67)$ apresentaram média consideravelmente superior aos demais grupos, não havendo uma tendência de linearidade na referida variável. As orientações de iniciação científica também não apresentaram uma tendência linear e sua maior média ocorreu no grupo dos pesquisadores categoria $2(4,8)$, seguido por bolsistas 1A (2,8), 1D (2), 1C (1,29) e 1B (1). Ressalta-se que, mesmo sendo a categoria mais elevada, os bolsistas nível 1A apresentaram média superior aos demais níveis da categoria 1.

Comparativamente com o triênio anterior - arrolaram-se apenas as orientações de iniciação científica, mestrado e doutorado, tendo em vista que as orientações de TCC e supervisões de pós-doutorado não foram investigadas por Leite et al. (2012) -, os 74 bolsistas investigados no triênio de 2007 a 2009 realizaram 303 orientações de iniciação científica (média de 4,1 por pesquisador), 539 orientações de mestrado (média de 7,3 por pesquisador) e 217 orientações de doutorado (média de 2,9 por pesquisador) (LEITE et al., 2012). No presente estudo, os 88 bolsistas retornaram 340 (média 3,86) orientações de iniciação científica, 363 (média 4,1) orientações de mestrado e 127 (média 1,44) orientações de doutorado.

Verifica-se que, nas três modalidades de orientações, a média de ocorrências foi superior no período de 2007 a 2010. Ressalta-se ainda que, em números absolutos, as orientações de doutorado foram superiores no período de 2007 a 2010, mesmo este dispondo de número menor de pesquisadores.

Logo, infere-se que o grupo de bolsistas de produtividade passou a concluir menos orientações por pesquisador. Tal cenário se contrapõe à expansão do número de programas de pós-graduação citado por Leite et al. (2012) e apresenta uma justificativa plausível aparente.

Em relação ao levantamento realizado com pesquisadores da área da Administração (PICININ, 2014), constatou-se que as maiores médias encontradas ocorreram nas orientações de mestrado. Não obstante, na área da Saúde Coletiva (SANTOS et al., 2009), também se observou uma prevalência na formação de mestres, seguida das orientações de doutorado. Este resultado coaduna com o encontrado em pesquisadores da área da Educação Física, ainda que, neste caso, bolsistas de produtividade de nível 1B apresentassem maior média de orientações em nível de doutorado.

A Tabela 9 apresenta o número de ocorrência de publicação de artigos classificados pelo Qualis 2012 da área da Educação Física em relação ao nível dos bolsistas de produtividade:

Tabela 9 - Número de ocorrência de artigos em periódicos por estrato do Qualis em relação ao nível da bolsa de produtividade.

\begin{tabular}{cccccccccc}
\hline & A1 & A2 & B1 & B2 & B3 & B4 & B5 & C & N/C \\
\hline 1A & 65 & 39 & 49 & 5 & 3 & 19 & 1 & 3 & 5 \\
1B & 19 & 23 & 34 & 4 & 2 & 3 & 1 & 2 & 0 \\
1C & 35 & 44 & 61 & 19 & 6 & 22 & 6 & 2 & 20 \\
1D & 82 & 94 & 109 & 11 & 10 & 27 & 4 & 14 & 20 \\
$\mathbf{2}$ & 287 & 324 & 623 & 181 & 44 & 160 & 22 & 48 & 48
\end{tabular}

Fonte: Autoria própria, 2015

Observa-se que bolsistas de todos os grupos concentram maior quantidade de sua produção em artigos A1, A2 e B1. Os bolsistas de nível 1A foram o único grupo que apresentam um número de publicações de artigos A1 (65) superior ao número de artigos A2 (39) e B1 (49). Nos demais grupos, verificou-se a tendência de que as publicações tendem a ser maiores nos periódicos do estrato B1 do Qualis, sendo menor o número de artigos A2 e, por sua vez, menor o número de artigos A1. 
Em todos os grupos, nota-se ainda uma considerável redução no número de publicações nos estratos B2 e inferiores, indicando que seu interesse está voltado para os periódicos com estratos superiores do Qualis.

A Tabela 10 apresenta a média de publicação de artigos classificados pelo Qualis 2012 da área da Educação Física em relação ao nível dos bolsistas de produtividade:

Tabela 10 - Média de publicações de artigos em periódicos por estrato do Qualis em relação ao nível da bolsa de produtividade.

\begin{tabular}{cccccccccc}
\hline & A1 & A2 & B1 & B2 & B3 & B4 & B5 & C & N/C \\
\hline 1A & 13 & 7,8 & 9,8 & 1 & 0,6 & 3,8 & 0,2 & 0,6 & 1 \\
1B & 6,33 & 7,67 & 11,33 & 1,33 & 0,67 & 1 & 0,33 & 0,67 & 0 \\
$\mathbf{1 C}$ & 5 & 6,29 & 8,71 & 2,71 & 0,86 & 3,14 & 0,86 & 0,29 & 2,86 \\
1D & 6,31 & 7,23 & 8,38 & 0,85 & 0,77 & 2,08 & 0,31 & 1,08 & 1,54 \\
$\mathbf{2}$ & 4,78 & 5,40 & 10,38 & 3,02 & 0,73 & 2,67 & 0,37 & 0,80 & 0,80 \\
\hline
\end{tabular}

Fonte: Autoria própria, 2015

Verifica-se uma tendência de queda na média de produções de artigos A1 e A2 conforme a diminuição do nível da bolsa, havendo uma pequena quebra em tal linearidade no grupo dos bolsistas nível 1C, que apresentaram média de produção de artigos A1 e A2 inferior ao grupo de bolsistas nível 1D.

Os resultados expostos por Weber et al. (2015), que analisaram as produções acadêmicas de bolsistas de produtividade de área da Psicologia no período de 2009 a 2011, apresentam uma tendência de queda de artigos publicados em periódicos A1 e A2 na medida em que o nível da bolsa diminui. Entretanto, verificou-se que tal fenômeno não ocorreu na área da Educação Física.

A concessão, a manutenção e a ascensão de categoria/nível da bolsa de produtividade por parte do CNPq não ocorrem por meio da avaliação das publicações a partir do Qualis, mas, sim, pela indexação das publicações nas bases SciELO, LILACS, EMBASE, ERIC, MEDLINE ou ISI. No entanto, ressalta-se que um dos critérios utilizados para a classificação dos periódicos no Qualis são as bases nas quais o periódico se encontra indexado, havendo estreita relação entre ambas as variáveis.

No que tange às publicações de artigos em periódicos A1, os bolsistas de produtividade nível 1A obtiveram a melhor média, distanciando-se demasiadamente dos demais grupos. Nos artigos publicados em periódicos A2 e B1, verifica-se que houve uniformidade entre todos os grupos.

Nota-se que as médias de publicações de artigos em periódico B2, B3, B4, B5, C e não classificados no Qualis são consideravelmente menores do que nos estratos superiores. Weber et al. (2015), de forma semelhante, também apontaram em seus resultados uma redução nas médias de publicação de artigos com Qualis B2 e inferiores em todos os níveis de bolsistas de produtividade da área da Psicologia.

Considerando o total de publicações, observa-se que houve um crescimento na média de publicações por pesquisador no triênio de 2010 a 2012 em comparação ao período de 2007 a 2009. Segundo Leite et al. (2012), os 74 pesquisadores com bolsa de produtividade no triênio de 2007 a 2009 publicaram 1.562 artigos, o que representa uma média de 21,10 artigos por pesquisador. Já em relação aos dados do presente estudo - desconsiderando os artigos publicados em periódicos não classificados no Qualis da área da Educação Física, tendo em vista que estes não foram contabilizados por Leite et al. (2012) -, os pesquisadores no triênio de 2010 a 2012 publicaram 2.507 artigos, o que representa uma média de 28,48 artigos por pesquisador. 
Desta forma, infere-se que a média de artigos publicados por pesquisador se elevou no triênio de 2010 a 2012 em relação ao triênio anterior (2007-2009). Este cenário coaduna com estudos que indicam que há um constante aumento da melhoria do desempenho na produção científica do Brasil (LEITE et al., 2012; COUTINHO et al., 2012). Verifica-se, neste sentido, que as publicações de pesquisadores da área da Educação Física encontram-se em expansão e acompanham o crescimento da produção científica do Brasil em suas diversas áreas do conhecimento.

No tocante à seção dos artigos por estrato do Qualis, verifica-se que, no triênio de 2010 a 2012, o maior número de ocorrências foi no estrato B1 (876), seguido dos estratos A2 (524), A1 (488), B4 (231), B2 (220), C (69), B3 (65) e B5 (34). Logo, constata-se que houve uma maior concentração nos estratos superiores do Qualis (respectivamente, B1, A2 e A1). No triênio anterior, Leite et al. (2012) constataram a existência de um cenário ligeiramente distinto. Ainda que tenha havido alterações no Qualis nestes períodos, verifica-se que os maiores números de ocorrências no período de 2007 a 2009 foram nos periódicos de estrato B1 (462), B2 (382) e A2 (2009).

Logo, nota-se que, ainda que os periódicos de estrato A1 tenham figurado entre as maiores frequências apenas no triênio de 2010 a 2012, há uma tendência na área da Educação Física de que as publicações dos bolsistas de produtividade se concentrem em periódicos com estrato mais elevado. Tal cenário replica-se em outras áreas do conhecimento, como na Enfermagem, no período de 2010 a 2012 (SANTOS et al., 2015).

Em comparação com a área da Administração (PICININ, 2014), na qual as publicações em periódicos de estrato A1, B4 e B5 apresentaram as menores médias, não houve replicação deste cenário na área da Educação Física, visto que as menores médias de publicação ocorreram nos periódicos de estrato B3, B5 e C. Ainda assim, em ambas as áreas, as menores médias ocorreram em periódicos de menor estrato, o que reforça a tendência por uma busca de publicações mais qualificadas em virtude das exigências do $\mathrm{CNPq}$ para a concessão da bolsa.

Fica evidenciado que os pesquisadores bolsistas de produtividade da área da Educação Física produzem um número de artigos publicados em periódicos consideravelmente superior às demais produções bibliográficas e produções técnicas e artísticas. Este cenário replica-se em outras áreas do conhecimento. Sacco et al. (2016), em estudo realizado na área da Psicologia, no período compreendido entre 2012 e 2014, verificaram maiores médias de publicações de artigos em comparação aos livros e capítulos de livros.

\section{Considerações finais}

A bolsa de produtividade do CNPq tem constituído um indicador que atesta a potencialidade dos pesquisadores e a distinção entre seus pares. Nesse contexto, ressalta-se a importância da visualização do panorama de produção técnico-científica desse grupo, considerado como elite no meio acadêmico.

A política de distribuição de bolsas de produtividade do CNPq procura premiar determinados tipos de pesquisa e pesquisadores que, sob a ótica das pessoas com poder de decisão nos cargos executivos da agência de fomento à pesquisa, representam o melhor para a área. Esta perspectiva de intervenção não é fruto da percepção de uma única pessoa, mas a construção de um consenso que vai levar em conta, também, a competição entre subáreas diferentes, a política nacional de desenvolvimento científico, a imprensa especializada e, em certa medida, a opinião pública expressada através dos meios de comunicação de massas.

Este conjunto de informações transcende os critérios objetivos de concessão da bolsa de produtividade, incorporando uma avaliação seletiva, por parte do pesquisador, das ações 
que acredita poderem aproximá-lo, mais rapidamente e com menos trabalho, ao seu objetivo específico (GUTIERREZ; ALMEIDA; MARQUES, 2016).

Os resultados apresentados neste artigo ilustram, além da exposição quantitativa da distribuição das bolsas, um retrato das tensões entre, de um lado, um projeto institucionalizado de política acadêmico-científica e, de outro, os movimentos de adequação e busca performática de sucesso para a obtenção da bolsa de produtividade, individuais ou num processo de alianças entre e intragrupos, por parte dos pesquisadores, percebidos aqui como sujeitos agentes de ações racionais, dotadas de um sentido que pode ser compreendido a partir das informações que dispõem no momento em que tomam suas decisões.

Nesse contexto, constatou-se, por meio da presente investigação, que os pesquisadores bolsistas de produtividade da área da Educação Física não priorizam publicações de artigos em congressos, de âmbito nacional ou internacional, bem como de livros, coletâneas e capítulos de livros. Também são reduzidas as produções técnicas e artísticas, sendo estas últimas praticamente nulas. Tal cenário encontrou respaldo na literatura por meio de pesquisas em outras áreas de conhecimento e, a priori, não parece se tratar de uma anormalidade.

Tal qual constatado em estudos de mesma natureza realizados em outras áreas do conhecimento, os bolsistas de produtividade da área da Educação Física apresentaram maior tendência de publicação de artigos em periódicos - especialmente nos estratos A1, A2 e B1 do Qualis da área da Educação Física - e na orientação de mestres e doutores.

Pondera-se que, tanto as orientações em nível de mestrado/doutorado quanto as publicações em periódicos indexados em bases de dados de excelência - que, por conseguinte, tendem a figurar nos estratos superiores do Qualis -, são requisitos para a manutenção ou a ascensão da categoria/nível da bolsa de produtividade. Desta forma, verifica-se que os pesquisadores objeto de estudo da presente investigação tendem a direcionar estrategicamente sua produção de acordo com as métricas estabelecidas pelo CNPq, o que explica o fato de algumas modalidades de publicação serem preteridas em relação às exigidas para a manutenção/ascensão da bolsa de produtividade.

Fica evidente, portanto, que o pesquisador age de forma consciente, a fim de maximizar seus resultados a partir do perfil requerido para a obtenção de bolsa de produtividade. Sendo assim, os critérios para a concessão da bolsa interferem diretamente na forma com que o pesquisador opta por divulgar os resultados de suas pesquisas.

Ainda que tal análise não tenha sido realizada no presente trabalho, ressalta-se que a dimensão heterogênea e multidisciplinar da Educação Física faz com que existam temáticas distintas e sem inter-relação abarcadas pela área. Essa característica fomenta o pressuposto de que exista desequilíbrio em número e/ou qualificação dos periódicos nas diversas subáreas que a compõem. Se confirmada a existência de tal dissensão, a competitividade na concessão/renovação da bolsa de produtividade é fragilizada, ao passo que pesquisadores inseridos em subáreas com maior número de periódicos classificados nos estratos superiores do Qualis têm mais possibilidades de serem contemplados em detrimento dos pesquisadores de outras subáreas.

A prossecução do presente estudo pode ser realizada por meio do acompanhamento da produção dos pesquisadores investigados, ou, ainda, por meio da realização de novo estudo no recém-encerrado quadriênio $\left(2013-2016^{2}\right)$ da avaliação da pós-graduação stricto sensu no Brasil.

\footnotetext{
${ }^{2}$ Conforme publicado na Resolução CAPES no 5 , de 11 de dezembro de 2014, a avaliação da pósgraduação stricto sensu no Brasil passa a ser quadrienal.
} 


\title{
ANALYSIS OF TECHNICAL-SCIENTIFIC PRODUCTION OF CNPQ RESEARCH- ERS GRANT IN PHYSICAL EDUCATION AREA IN 2010-2012 TRIENNIUM
}

\begin{abstract}
This study objectified to analyze the technical-scientific production of researchers grant in Physical Education area in 2010-2012 triennium. The list of researchers grant was obtained through CNPq website, so their curriculum was searched in Lattes Platform and we accounted through scriptLattes v8.07 software their bibliographical, technical and artistic production such as completed guidance. We found that they primarily look for publications in Qualis A1, $\mathrm{A} 2$ and $\mathrm{B} 1$ journals, as well as master and $\mathrm{PhD}$ guidance. We concluded that researchers grant in Physical Education tend to direct their production to meet the requirements stipulated by the CNPq for maintenance/rise of the grant.

Keywords: Research support. Scientific publication indicators. Physical Education and training.

\section{ANÁLISIS DE LA PRODUCCIÓN TÉCNICO-CIENTÍFICA DEL LOS PESQUISI- DORES CON BECA DE PRODUCTIVIDAD EN EL ÁREA DE EDUCACIÓN FÍSICA EN EL TRIENIO 2010-2012}

\begin{abstract}
Resumen
Este estudio tiene el objetivo de analizar la producción técnico-científica de los becarios de productividad del área de Educación Física durante el periodo 2010 a 2012. La lista de los becarios de productividad se obtuvo a través de la página electrónica del $\mathrm{CNPq}$, loscurrículos correspondientes se buscaron posteriormente en la Plataforma Lattes y la producción bibliográfica, técnica y artística, bien como las orientaciones finalizadas identificadas en esos currículos se contabilizaron a través del software scriptLattes v8.07. Se constató que esos becarios buscan principalmente publicaciones en periódicos con Qualis A1, A2 y B1, así como orientaciones de maestría y doctorado. Se concluye que los pesquisidores con beca de productividad en el área de Educación Física tienden a dirigir su producción a la finalidad de cumplir con los requisitos estipulados por el CNPq para el mantenimiento/progresión de la beca.
\end{abstract}

Palabras clave: Apoyo a la Investigación como Asunto. Indicadores de producción científica. Educación física y entrenamiento.

\section{Referências}

CAPES. Coordenação de Aperfeiçoamento de Pessoal de Nível Superior. WebQualis, 2013. Disponível em: <https://qualis.capes.gov.br/>. Acesso em: 15 jul. 2014.

COUTINHO, R.; DÁVILA, E. S.; SANTOS. W. M.; ROCHA, J. B. T.; SOUZA, D. O. G.; FOLMER, V.; PUNTEL, R. L. Brazilian scientific production in science education. Scientometrics, v. 92, n. 3, p. 697-710, sep. 2012.

CNPq. Conselho Nacional de Desenvolvimento Científico e Tecnológico. RN-016/2006. 2006. Disponível em: 〈www.cnpq.br/normas/rn 06 016.htm>. Acesso em: 31 ago.2013.

CNPq. Conselho Nacional de Desenvolvimento Científico e Tecnológico. . Comitê de Assessoramento de Educação Física, Fonoaudiologia, Fisioterapia e Terapia Ocupacional - CAMS, 2010. Disponível em: <memoria.cnpq.br/cas/ca-ms.htm>. Acesso em: 31 ago. 2013. 
CNPq. Conselho Nacional de Desenvolvimento Científico e Tecnológico. . Bolsas em curso, CNPq, 2013. Disponível em: http://plsql1.cnpq.br/divulg/RESULTADO_PQ_102003.curso. Acesso em: 31 ago. 2013.

FURTADO, H. L.; NAMAN, M. Formação do pesquisador em Educação Física: análises epistemológicas. Pensar a prática, Goiânia, v. 17, n. 3, p. 751-765, jul./set. 2014.

GUTIERREZ, G. L. Alianças e grupos de referência na produção do conhecimento. Campinas: Autores Associados, 2005.

GUTIERREZ, G. L.; ALMEIDA, M. A. B.; MARQUES, R. F. F. Apropriação das ciências humanas pela Educação Física: análise dos processos de classificação no Brasil entre os anos de 2007 a 2012. Revista Brasileira de Educação Física e Esporte, São Paulo, v. 30, n. 4, p. 937-949, out./dez. 2016.

LEITE, B. D. G. L.; OLIVEIRA, E. A.; QUEIROZ, I. N.; MARTELLI, D. R. B.; OLIVEIRA, M. C.; MARTELLI JR.; H. Profile of the researchers with productivity grants in the Brazilian National Research Council (CNPq) of the physical education area. Motricidade, Ribeira de Pena, v. 8, n. 3, p. 90-98, jul. 2012.

MARTELLI-JUNIOR, H.; MARTELLI, D. R. B.; QUIRINO, I. G.; OLIVEIRA, M. C. L. A.; LIMA, L. S.; OLIVEIRA, E. A.. Pesquisadores do CNPq na área de medicina: comparação das áreas de atuação. Revista da Associação Médica Brasileira, São Paulo, v. 56, n. 1, p. 478-483, maio. 2010.

MENA-CHALCO, J. P; CESAR JUNIOR, R. M. ScriptLattes: an open-source knowledge extraction system from the Lattes platform. Journal of the Brazilian Computer Society, Campinas, v. 15, n. 4, p. 31-39, dec. 2009.

MENDES, P. H. C. ; MARTELLI, D. R. B.; SOUZA, W. P. S.; QUIRINO FILHO, S.; MARTELLI-JÚNIOR, H.. Perfil dos pesquisadores bolsistas de produtividade científica em medicina no CNPq, Brasil. Revista Brasileira de Educação Médica, Rio de Janeiro, v. 34, n. 4, p. 535-541, out./dez. 2010.

OLIVEIRA, E. A.; PÉCOITS-FILHO, R.; QUIRINO, I. G.; OLIVEIRA, M. C.; MARTELLI, D. R.; LIMA, L. S.; MARTELLI-JR., H.. Perfil e produção científica dos pesquisadores do CNPq nas áreas de Nefrologia e Urologia. Jornal Brasileiro de Nefrologia, São Paulo, v. 33, n. 1, p. 31- 37, jan./mar. 2011a.

OLIVEIRA, E. A.; RIBEIRO, A. L. P.; QUIRINO, I. G.; OLIVEIRA, M. C. L.; MARTELLI, D. R.; LIMA, L. S.; COLOSIMO, E. A.; LOPES, T. J.; SILVA, A. C. S.; MARTELlIJUNIOR, H. Pesquisadores do Conselho Nacional de Desenvolvimento Científico e Tecnológico na área de Cardiologia. Arquivos Brasileiros de Cardiologia, São Paulo, v. 97, n. 3, p. 186-193, ago. $2011 \mathrm{~b}$.

OLIVEIRA, J. C. ; MARTINS, C.; BORBA, J. A.; SILVA, R. F. C. Traçando o perfil dos pesquisadores em produtividade (PQ) do CNPQ da área de Administração e Contabilidade. In: ENCONTRO DE ENSINO E PESQUISA EM ADMINISTRAÇÃO E CONTABILIDADE, 1., 2007, Recife. Anais... Recife: ANPAD, 2007. p. 1-10. 
PAIXÃO, J. A; CUSTÓDIO, G. C. C; BARROSO, Y. W. S. Atuação de licenciados em Educação Física nas academias de ginástica: Uma análise a partir dos saberes docentes. Pensar a prática, Goiânia, v. 17, n. 3, p. 701-717, jul./set. 2014.

PICININ, C. T. A produção técnico-científica dos bolsistas de produtividade e professores dos programas de pós-graduação da área da administração: uma análise da área no triênio 2010-2012. 2014. 335 f. Tese (Doutorado em Administração) - Programa de PósGraduação em Administração, Universidade Positivo, Curitiba, 2014.

SACCO, A. M. ; VILANOVA, F.; SOUSA, D. A.; VALIENTE, L.; WENDT, G. W.; KOLLER, S. H. Perfil dos bolsistas de produtividade em pesquisa do $\mathrm{CNPq}$ atuantes em psicologia no triênio de 2012-2014. Psicologia: Ciência e Profissão, Brasília, v. 36, n. 2, p. 392-303, abr./jun. 2016.

SANTOS, S. M. C.; LIMA, L. S.; MARTELLI, D. R. B.; MARTELLI-JÚNIOR, H. Perfil dos pesquisadores da Saúde Coletiva no Conselho Nacional de Desenvolvimento Científico e Tecnológico. Physis: Revista de Saúde Coletiva, Rio de Janeiro, v. 19, n. 3, p. 761-775, set./mai. 2009.

SANTOS, W. M.; PADOIN, S. M. M.; LACERDA, M. R.; GUETERRES, E. C. Perfil dos pesquisadores bolsistas de produtividade em pesquisa na área de enfermagem. Revista de Enfermagem da UFPE, Recife, v. 9, n. 2, p. 844-850, fev. 2015.

SCARPELLI, A. C. ; SARDENBERG, F.; GOURSAND, D.; PAIVA, S. M.; PORDEUS, I.A. Academic trajectories of dental researchers receiving CNPq's productivity grants. Brazilian Dental Journal, Ribeirão Preto, v. 19, n. 3, p. 252-256, jul. 2008.

SPILKI, F. R. Perfil dos bolsistas de produtividade do Conselho Nacional de Desenvolvimento Científico e Tecnológico $(\mathrm{CNPq})$ na área de Medicina Veterinária. Pesquisa Veterinária Brasileira, Rio de Janeiro, v. 33, n. 2, p. 205-213, fev. 2013.

WEBER, J. L. A. ; RAMOS, C.C.; MESTER, A.; LINDERN, D.; HÖRLLE, K.R.; SOUZA, C.S.; PIZZINATO, A.; ROCHA, K.B. Perfil dos pesquisadores bolsistas de produtividade científica em Psicologia do Conselho Nacional de Desenvolvimento Científico e Tecnológico. Estudos de Psicologia, Campinas, v. 32, n. 1, p. 1-11, jan./mar. 2015.

Recebido em: 05/08/2016

Revisado em: 08/02/2017

Aprovado em: 11/09/2017

Endereço para correspondência:

prof.brunopedroso@gmail.com

Bruno Pedroso

Universidade Estadual de Ponta Grossa

Av. General Carlos Cavalcanti, 4748,

CEP 84030-900 - Ponta Grossa - PR 